\title{
Uji karakteristik nyala api pembakaran premix bioetanol dari ampas tebu
}

\author{
Saeful Bakhri ${ }^{*}$, Djoko Wahyudi ${ }^{2}$, Alief Muhammad ${ }^{3}$ \\ 1,2,3 Jurusan Teknik Mesin, Fakultas Teknik, Universitas Panca Marga \\ Jl. Yos Sudaarso 107 Pabean Dringu Probolinggo 67271 \\ ${ }^{*}$ Corresponding author: saeful.bai@gmail.com
}

\begin{abstract}
The fuel demand is very important in this day. The higher fuel consumption was impact depletion of existing reserves of oil resources. Bioethanol is one of the energy conversions from biomass containing sugar, starch and cellulose become fuel. Bagasse is a solid waste containing a lignocellulotic substrate which has the potential for bioethanol production. The purpose of this experiment was to determine the flame characteristics of the composition of the addition bioethanol to Pertamax as a mixture, with a variety of mixtures (B0, B5, B10 and B15). The test was carried out using the premix combustion method. The data from the result experiment were analyzed using descriptive methods. The results of the experiment showed that the addition of bioethanol can affect the flame characteristics. The shape of the flame changes from a conical shape to an enlarged cone angle along with the addition of a percentage. The flame height has decreased, the highest flame is at BO with value of $12.79 \mathrm{~mm}$, the lowest flame height is at B15 with value $10.27 \mathrm{~mm}$. Combustion velocity has increased, the highest velocity is at B15 with value of $32.753 \mathrm{~cm} / \mathrm{s}$ and the lowest velocity is at BO with value of $22.253 \mathrm{~cm} / \mathrm{s}$.
\end{abstract}

Keywords: energy conversion, bioethanol, bagasse, flame characteristics, premix combustion.

\begin{abstract}
Abstrak
Kebutuhan bahan bakar menjadi hal yang sangat penting pada zaman sekarang ini. Semakin tingginya konsumsi bahan bakar mengakibatkan menipisnya cadangan sumber daya minyak yang ada. Bioetanol merupakan salah satu konversi energi dari biomassa yang mengandung gula, pati maupun selulosa menjadi bahan bakar. Ampas tebu termasuk limbah padat yang mengandung substrat lignoselulotik yang berpotensial untuk produksi bioetanol. Tujuan penelitian ini adalah untuk mengetahui karakteristik api terhadap komposisi penambahan bioetanol pada pertamax sebagai campurannya, dengan variasi campuran (B0, B5, B10 dan B15). Pengujian dilakukan dengan menggunakan metode pembakaran premix. Data hasil pengujian dianalisis menggunakan metode deskriptif. Hasil dari penelitian menunjukkan penambahan bioetanol dapat mempengaruhi karakteristik api. Bentuk api mengalami perubahan dari bentuk kerucut mengalami perbesaran sudut kerucut seiring dengan penambahan prosentase. Tinggi nyala api mengalami penurunan, nyala api tertinggi pada B0 dengan nilai $12,79 \mathrm{~mm}$, tinggi nyala api terendah pada B15 dengan nilai 10,27 mm. Kecepatan Pembakaran mengalami kenaikan, kecepatan tertinggi pada B15 dengan nilai $32,753 \mathrm{~cm} / \mathrm{s}$ dan kecepatan terendah pada B0 dengan nilai $22,253 \mathrm{~cm} / \mathrm{s}$.
\end{abstract}

Kata kunci: konversi energi, bioetanol, ampas tebu, karakteristik api, pembakaran premix.

\section{Pendahuluan}

Kebutuhan bahan bakar menjadi hal yang sangan penting pada zaman sekarang ini. Cadangan minyak bumi Indonesia 3,6 milliar barrel diperkirakan akan habis dalam 13 tahun mendatang [1]. Pemerintah dalam mengatasi masalah tersebut mengeluarkan PP No 79 Tahun 2014 
Tentang Kebijakan Energi Nasional, dimana terwujudnya energi primer yang optimal pada tahun 2025 peran enegeri baru dan enegri terbarukan paling sedikit $23 \%$ [2].

Bioetanol adalah alkohol yang berasal dari tumbuh-tumbuhan seperti jagung, gandum, kentang dan tebu [3]. Tebu merupakan tanaman yang digunakan sebagai bahan baku pembuatan gula. Limbah sisa penggilingan batang tebu disebut ampas/bagas. Ampas tebu mengandung substrat lignoselulostik potensial untuk produksi bioetanol. sebanyak 200 gram ampas tebu yang ditambahkan ragi roti dan urea 1 gram sebagi nutrisi, kemudian difermentasikan selama 4 hari menghasilkan etanol dengan kadar 28,55\% [4]. Salah satu fungsi dari alkohol pada bahan bakar yaitu sebagai octane booster. Penambahan etanol 5\% dan $10 \%$ dengan bahan bakar bensin terbukti menambahkan nilai oktan bahan bakar menjadi 89,6 dan 91,2 dan mengalami penurunan emisi gas buang karbon monoksida $(\mathrm{CO})$, karbon dioksida $\left(\mathrm{CO}_{2}\right)$ dan hidrokarbon (HC) [5].

Pengujian Bioetanol dari umbi gayong dengan lampu bersumbu menghasilkan tinggi nyala api campuran bahan bakar premium dan bioethanol cenderung fluktuatif naik dan turun. Kenaikan terjadi pada persentase campuran E10\% dengan tinggi $60 \mathrm{~mm}$ dan $\mathrm{E} 40 \%$ dengan tinggi $62 \mathrm{~mm}$. Sedangkan pada campuran E100 langsung turun drastis[6].

Penggunaa campuran bioethanol dalam pertamax dalam uji kinerja didapat pada campuran $15 \%$ bioethanol dan $85 \%$ pertamax menghasilkan kinerja maksimal. Torsi maksimal sebesar 9,32 N.m pada putararan $2400 \mathrm{rpm}$. Daya efektif maksimal sebesar $4,77 \mathrm{kw}$ pada putaran mesin 2400 rpm[7].

Pembakaran adalah suatu reaksi
kimia antara bahan bakar dan
pengoksidasian (oksigen atau udara) yang
menghasilkan panas dan cahaya [8].
Karakteristik Api pembakaran dapat
diketahui melalui pengujian pembakaran, baik pembakaran premixed maupun non premixed. Pembakaran premixed adalah proses pembakaran dimana bahan bakar dan udara dicampur dalam ruang mixing chamber [9]. Bentuk nyali api menunjukkan bahwa pembakaran mendekati sempurna atau tidak. Pembakaran sempurna akan menghasilkan energi pembakaran yang besar dan tidak menghasilkan gas yang berbahaya [10].

Berdasarkan uraian diatas, maka perlu dilakukan penelitian mengenai pengujian karakteristik api pembakaran antara campuran bioetanol terhadap bahan bakar pertamax dengan metode pembakaran premix.

Tujuan dari penelitian ini adalah untuk mengetahui pengaruh prosentase campuran bioetanol ampas tebu pada pertamax terhadap bentuk nyala api, tinggi nyala api, dan kecepatan pembakaran.

\section{Tinjauan Pustaka}

Variasi Air Fuel Ratio (AFR) juga mempengaruhi tinggi nyala api. Semakin tinggi nilai Air Fuel Ratio (AFR) semakin berkurang tinggi nyala apinya, sebaliknya semakin rendah nilai Air Fuel Ratio (AFR) semakin meningkat tinggi nyala api yang terbentuk. Semakin besar nilai Air Fuel Ratio (AFR) menyebabkan kecepatan reaktan semakin bertambah [11].

- Air Fuel Ratio/AFR

Air Fuel Rasio dapat dihitung dengan rumus[12]:

$A F R=\frac{m_{a}}{m_{f}}$

Keterangan:

$\mathrm{m}_{\mathrm{a}}=$ laju massa udara

$\mathrm{m}_{\mathrm{f}}=$ laju massa bahan bakar

- Rasio Ekivalen $(\boldsymbol{\phi})$

Rumus rasio ekivalen adalah sebagai berikut[12]:

$\phi=\frac{A F R_{S}}{A F R_{a}}$

Keterangan:

$\mathrm{AFR}_{\mathrm{S}}=$ Rasio udara-bahan bakar stoikiometri

AFRa = Rasio udara-bahan bakar actual 
- Kecepatan Pembakaran

Kecepatan reaktan dapat dihitung dengan rumus[13]:

$\mathrm{v}=\frac{\text { Qfuel }+ \text { Qreaktan }}{A}$

Keterangan:

$$
\begin{array}{ll}
\mathrm{V} & =\text { kecepatan reaktan } \\
\mathrm{Q}_{\text {fuel }} & =\text { debit bahan bakar } \\
\mathrm{Q}_{\text {reaktan }} & =\text { debit udara } \\
\mathrm{A} & =\text { luas penampang burner }
\end{array}
$$

Setelah mendapat kecepatan reaktan, maka kecepatan pembakaran dapat dihitung dengan rumus:

$S_{L}=\mathrm{v} \cdot \sin \alpha$

Keterangan:

$\mathrm{S}_{\mathrm{L}}=$ Kecepatan api laminar $(\mathrm{cm} / \mathrm{s})$

$\mathrm{v}=$ Kecepatan reaktan $(\mathrm{cm} / \mathrm{s})$

$\alpha=$ Sudut api yang terbentuk $\left({ }^{0}\right)$

\section{Metode Penelitian}

Metode yang digunakan pada penelitian ini adalah metode ekperimental (experimental research). Data-data yang diperoleh nantinya akan diolah ke dalam grafik dan di analisa sehingga membentuk suatu pola kecenderungan tertentu yang nantinya akan ditarik menjadi sebuah kesimpulan tentang objek yang diteliti.

Varaibel yang digunakan dalam penelitian ini adalah :

1. Variabel bebas

Variabel bebas dalam penelitian ini adalah :

- B0 (100\% pertamax $+0 \%$ bioetanol)

- B5 (95\% pertamax $+5 \%$ bioetanol)

- B10 (90\% pertamax $+10 \%$ bioetanol)

- B15 (85\% pertamax $+15 \%$ bioetanol)

2. Variabel terikat

Variabel terikat pada penelitian ini adalah bentuk nyala api, tinggi nyala api, dan kecepatan pembakaran.

3. Variabel terkontrol

variabel terkontrol dalam penelitian ini adalah:

- Diameter burner 4,5 mm

- Waktu pembakaran dilakukan pada ruang gelap.

- Bioetanol dari ampas tebu dengan kadar $19 \%$.

- Laju aliran bahan bakar dibuat tetap.
- Rasio Ekivalen $\phi=1,2$

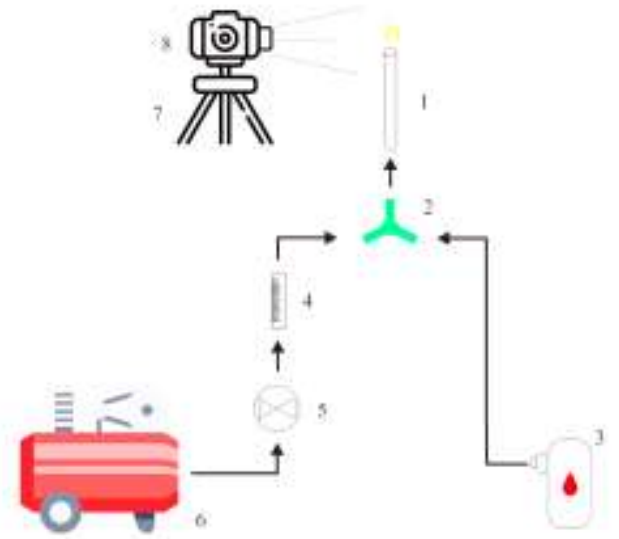

1. Burner

5. Katup udara

2. Nepel $Y$

6. Kompressor

3. Nano Spray

7. Tripod

4. Flow meter udara

8. Kamera

Gambar 1. Skema Instalasi Penelitian

Pertama-pertama

sebelum

melakukan pengambilan data terlebih dahulu menghitung kebutuhan bahan bakar dari masing-masing campuran. Masingmasing campuran bahan bakar dimasukkan ke dalam nano spray sebanyak $10 \mathrm{ml}$. Kemudian katup udara dibuka sesuai dengan perhitungan dengan melihat flow meter udara. Nano spray dinyalakan, kemudian percikan api dengan menggunakan pemantik elektrik. Hasil nyala api direkam dalam bentuk video dengan menggunakan kamera dengan camera high speed 30fps kemudian dikonversi menjadi gambar dengan menggunakan software $d v d$ video soft. Hasil gambar tinggi nyala diukur tinggi api dan sudut api dengan menggunakan software image-j. Data hasil pengukuran dimasukkan ke Microsoft Excel dan dirubah ke dalam grafik. Lebih jelasnyaa dapat dilihat pada gambar 2 daigram alir penelitian yang dilakukan selama penelitian ini berlangsung. 


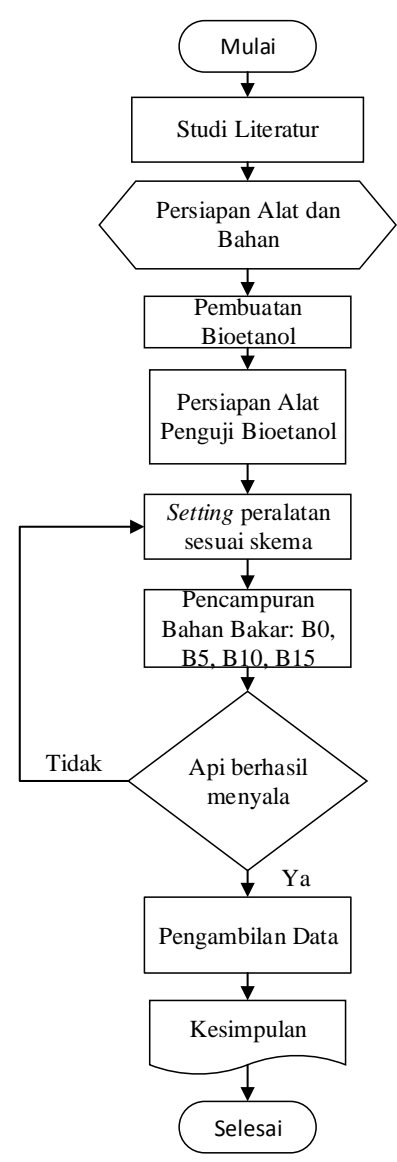

Gambar 2. Diagram Alir Penelitian

\section{Hasil dan Pembahasan}

a) Visualisasi Nyala Api

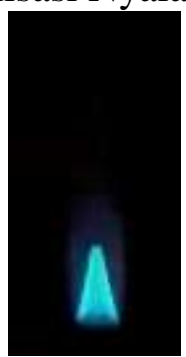

(a)

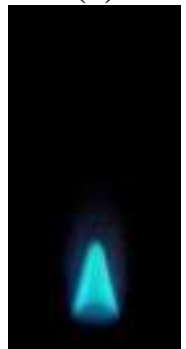

(c)

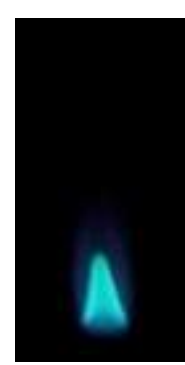

(b)

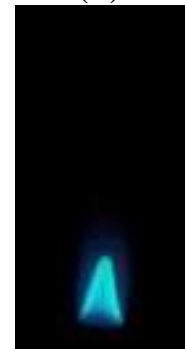

(d)
Gambar 3. Visualisai Nyala Api : a) B0, b) B5, c) B10, d) B15

Berdasarkan gambar 3 menunjukkan bahwa bentuk pola Api premix berbentuk kerucut dan terdapat 2 layer kerucut, menandakan bahwa pembakaran yang terjadi adalah campuran kaya. Terlihat pada gambar layer yang pertama berbentuk kerucut dengan warna biru tebal, sedangkan layer yang kedua pada bagian luar kerucut berbentuk elips dengan warna biru yang tipis. Hal tersebut terjadi karena bahan bakar yang terbakar jauh lebih banyak dibandingkan dengan udara, sehingga bahan bakar yang berlebih itu terbakar secara difusi dengan udara lingkungan sekitar api. Bentuk kerucut pada nyala api mengalami perbesaran sudut seiring dengan penambahan prosentase bioetanol.

b) Tinggi Nyala Api

Tabel 1. Tinggi Nyala Api

\begin{tabular}{lcccc}
\hline \multirow{2}{*}{ Bioetanol (B) } & \multicolumn{4}{c}{ Pengujian (P) } \\
\cline { 2 - 5 } & P1 & P2 & P3 & Rata-rata \\
\hline B0 & 12,41 & 13,12 & 12,85 & 12,79 \\
\hline B5 & 11,78 & 12,08 & 12,15 & 12,00 \\
\hline B10 & 11,37 & 11,20 & 11,68 & 11,42 \\
\hline B15 & 10,31 & 10,25 & 10,24 & 10,27 \\
\hline
\end{tabular}

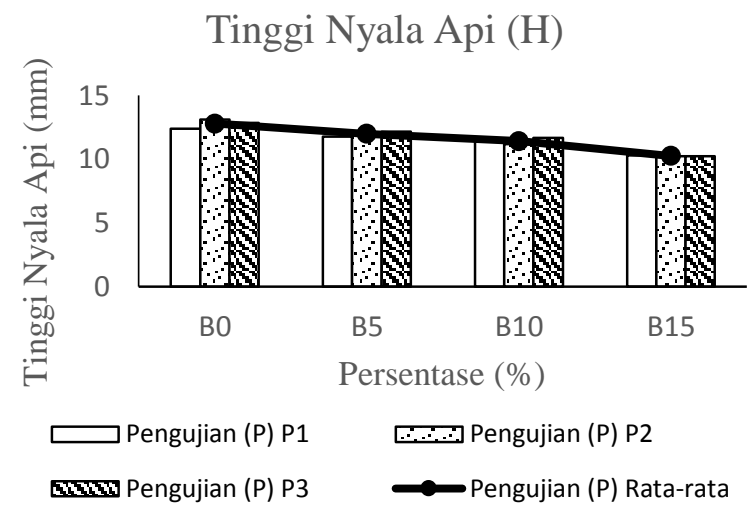

Gambar 4. Grafik Tinggi Nyala Api

Berdasarkan Tabel 1 dan Gambar 4 menunjukkan bahwa pembakaran dengan bahan bakar pertamax murni B0 dihasilkan tinggi nyala api rata-rata sebesar $12,79 \mathrm{~mm}$. Penambahan bioetanol ampas tebu pada B5 menghasilkan tinggi nyala api rata-rata sebesar 12,00 mm, pada campuran B10 menghasilkan tinggi nyala api rata-rata sebesar $11,42 \mathrm{~mm}$ dan pada campuran bioetanol B15 menghasilkan tinggi nyala api rata-rata sebesar $10,27 \mathrm{~mm}$. Dari hasil 
penelitian dapat dianalisa bahwa penambahan bioetanol ampas tebu dapat menurunkan tinggi nyala api seiring dengan penambahan prosentase campurannya.

c) Kecepatan Pembakaran

Menghitung kecepatan pembakaran terlebih dahulu mengukur sudut nyala api, Adapun sudut nyala api dapat dilihat pada tabel 2.

Tabel 2. Sudut Nyala Api

\begin{tabular}{lcccr}
\hline \multirow{2}{*}{ Bioetanol (B) } & \multicolumn{4}{c}{ Pengujian (P) } \\
\cline { 2 - 5 } & P1 & P2 & P3 & Rata-rata \\
\hline B0 & 12,73 & 11,82 & 12,23 & 12,26 \\
\hline B5 & 14,06 & 13,88 & 13,62 & 13,86 \\
\hline B10 & 15,74 & 16,02 & 15,61 & 15,79 \\
\hline B15 & 18,13 & 18,27 & 19,04 & 18,48 \\
\hline
\end{tabular}

Data sudut nyala api kemudian diolah hingga mendapatkan nilai kecepatan pembakaran. Nilai kecepatan pembakaran dapat dilihat pada tabel 3 .

Tabel 3. Kecepatan Pembakaran

\begin{tabular}{lcccr}
\hline \multirow{2}{*}{ Bioetanol (B) } & \multicolumn{4}{c}{ Pengujian (P) } \\
\cline { 2 - 5 } & P1 & P2 & P3 & Rata-rata \\
\hline B0 & 23,10 & 21,46 & 22,20 & 22,25 \\
\hline B5 & 25,36 & 25,05 & 24,58 & 25,00 \\
\hline B10 & 28,19 & 28,67 & 27,95 & 28,27 \\
\hline B15 & 32,15 & 32,40 & 33,71 & 32,75 \\
\hline
\end{tabular}

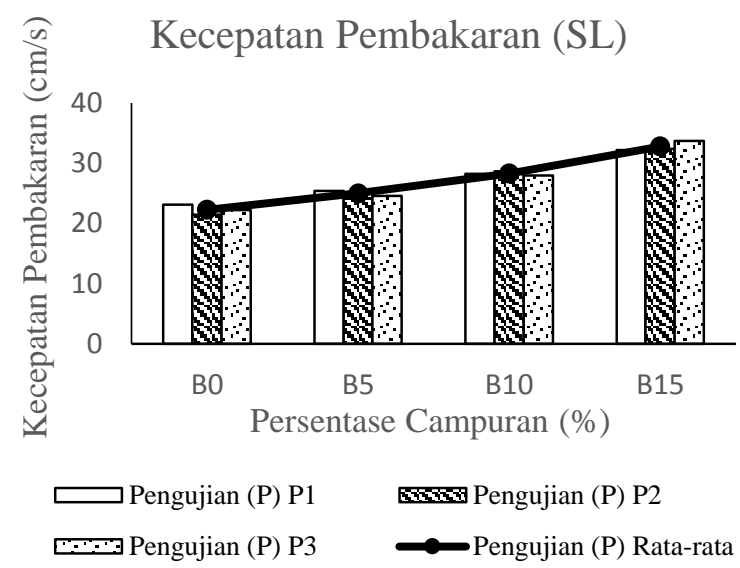

Gambar 5. Grafik Kecepatan Pembakaran

Berdasarkan tabel 3 dan gambar 5 menunjukkan bahwa pembakaran dengan bahan bakar pertamax murni B0 dihasilkan kecepatan pembakaran rata-rata sebesar $22,253 \mathrm{~cm} / \mathrm{s}$. Penambahan bioetanol dari ampas tebu pada pada campuran B5 dihasilkan kecepatan pembakaran dengan rata-rata sebesar 24,996 cm/s, pada campuran B10 dihasilkan kecepatan pembakaran dengan rata-rata sebesar $28,269 \mathrm{~cm} / \mathrm{s}$, dan pada campuran B15 dihasilkan rata-rata kecepatan pembakaran sebesar $32,753 \mathrm{~cm} / \mathrm{s}$. Dari hasil penelitian dapat dianalisa bahwa penambahan bioetanol dapat meningkatkan kecepatan pembakaran (SL). Kecepatan pembakaran meningkat seiring dengan penambahan prosentase bioetanol. Hal ini terjadi dikarenakan proses oksidasi terjadi lebih cepat saat menggunakan bioetanol dan campurannya [14]. Kandungan oksigen pada bioetanol, pada saat dipanaskan akan bereaksi terlebih dahulu dengan atom $\mathrm{C}$ (karbon) dan atom $\mathrm{H}$ (hidrogen), sehingga menyebabkan reaksi pembakaran menjadi semakin cepat [15]-[17].

\section{Kesimpulan}

Pengaruh prosentase penambahan bioetanol pada pertamax yaitu terhadap bentuk nyala api berbentuk kerucut dan terdapat 2 layer kerucut hal ini menunjukkan pembakaran yang terjadi adalah campuran kaya. Bentuk nyala api mengalami perubahan dari bentuk kerucut mengalami perbesaran sudut seiring dengan penambahan prosentase campuran. Tinggi nyala api mengalami penurunan, nyala api tertinggi pada $\mathrm{B} 0$ dengan rata-rata tinggi nyala api $12,79 \mathrm{~mm}$ dan tinggi nyala api terendah pada B15 dengan rata-rata tinggi nyala api 10,27 mm. Kecepatan pembakaran mengalami kenaikan, Kecepatan pembakaran tertinggi pada B15 dengan nilai $32,753 \mathrm{~cm} / \mathrm{s}$ dan kecepatan pembakaran terendah pada B0 dengan nilai $22,253 \mathrm{~cm} / \mathrm{s}$.

\section{Referensi}

[1] A. F. Sa'adah, A. Fauzi, and B. Juanda, "Peramalan Penyediaan dan Konsumsi Bahan Bakar Minyak Indonesia dengan Model Sistem Dinamik," J. Ekon. dan Pembang. 
Indones., vol. 17, no. 2, pp. 118-137, 2017, doi: 10.21002/jepi.v17i2.661.

[2] P. P. R. Indonesia, PP No. 79 Thn 2014 Tentang Kebijakan Energi Nasional. 2014, pp. 1-36.

[3] S. H. Susilo and A. M. Sabudin, "Pengaruh Campuran Bioetanol Pertamax 92 Terhadap Kinerja Motor Otto," J. Energi dan Teknol. Manufaktur, vol. 1, no. 02, pp. 2126, 2018, doi: 10.33795/jetm.v1i02.21.

[4] Irvan, Popphy Prawati, and Bambang Trisakti, "Pembuatan Bioetanol Dari Tepung Ampas Tebu Melalui Proses Hidrolisis Termal Dan Fermentasi: Pengaruh Ph, Jenis Ragi, Dan Waktu Fermentasi," $J$. Tek. Kim. USU, vol. 4, no. 2, pp. $27-$ 31, 2015, doi: 10.32734/jtk.v4i2.1467.

[5] B. Sulistyo, J. Sentanuhady, A. Susanto, T. Dwi, and E. Fitriani, "Pemanfaatan etanol sebagai octane improver bahan bakar bensin pada sistem bahan bakar injeksi sepeda motor 4 langkah 1 silinder," Thermofluid Semin. Nas., vol. 3, no. November, pp. 196-200, 2009.

[6] Y. P. D. Prasetyo, "Analisis Kinerja Nyala Api Bioethanol dari Umbi Ganyong (Canna edulis kerr)," Jtm, vol. 07, no. 01, pp. 73-78, 2019.

[7] A. Prasetya, Rifky, and M. Yusuf D, "Pengaruh Penggunaan Campuran Bioetanol dari Biji Cempedak dalam Pertamax terhadap Kinerja Motor Matik," Pros. Semin. Nas. Teknoka, vol. 4, no. 2502, pp. 44-58, 2020, doi: 10.22236/teknoka.v4i0.4290.

D. Wahyudi, "PERILAKU RAMBAT API PREMIXED PENYALAAN BAWAH CAMPURAN GAS METANAUDARA INHIBITOR NITROGEN ( N 2 )," vol. 2, no. 2, pp. 1-6, 2013.

[9] B. N. Riwu, Defmit, I. N. G. Wardana, and L. Yuliati, "Kecepatan
Pembakaran Premixed Campuran Minyak Jarak - Liquefied Petroleum Gas (LPG) pada Circular Tube Burner," J. Rekayasa Mesin, vol. 7, no. 2, pp. 41-47, 2016, doi: 10.21776/ub.jrm.2016.007.02.1.

[10] B. Irawan, J. Teknik, M. Politeknik, and N. Malang, "Perhitungan Energi Pembakaran Bahan Bakar di Dalam Silinder Mesin Bensin," Politek. Negeri Malang, vol. 3, no. December 2018, pp. 3-6, 2017.

[11] D. Perdana and E. Gunawan, "Perilaku Dan Kestabilan Nyala Api Pada Pembakaran Premixed Minyak Biji Kapas Terhadap Variasi Air Fuel Ratio," Perilaku Dan Kestabilan Nyala Api Pada Pembakaran Premixed Miny. Biji Kapas Terhadap Variasi Air Fuel Ratio, vol. 2018, no. November, pp. 239-246, 2018.

[12] C. P. Mahandari, "Fenomena flame lift-up pada pembakaran premixed gas propana," Jakarta Univ. Indones., 2010.

[13] H. F. Al-Mahbuby, "Karakteristik Pembakaran Premix Biosolar Dengan Penambahan Biodiesel Minyak Jelantah," 2019.

[14] E.; M. Prasetyo, Romadhon, Fitrianto, "Unjuk Kerja Api Dari Bioetanol Umbi Walur ( Amorphopallus Variabilis )," JPTM Univ. Negeri Surabaya, vol. 08, no. 2006, pp. 6-11, 2019.

[15] Arwin, L. Yulianti, and A. S. Widodo, "Karakteristik Pembakaran Droplet Campuran Bahan Bakar Bensin-Etanol," Semin. Nas. Inov. dan Apl. Teknol. Ind. 2019, pp. 291296, 2019.

[16] A. Prasetiyo, S. Sukarni, R. Wulandari, A. E. Widiono, $\mathrm{H}$. Suryanto, and U. Yanuhar, "Investigation on kinetic parameters during combustion of Tetraselmis chuii microalgae under thermogravimetric analyzer," AIP 
Conf. Proc., vol. 2255, no. September, 2020, doi: 10.1063/5.0013582.

[17] A. A. Permanasari, S. Sukarni, R. Wulandari, P. Puspitasari, M. N. Mauludi, and R. Ramadani, "Density, flash point, viscosity, and heating value of waste cooking biodiesel (B20) with bioadditive essential oil (lemon, lemongrass, eucalyptus)," J. Phys. Conf. Ser., vol. 1595, no. 1, 2020, doi: 10.1088/1742-6596/1595/1/012005. 